\title{
The De-politicization of Internet Literature in China
}

\author{
${ }^{1}$ Ruixia Han, ${ }^{2}$ Shaohua Huang \\ ${ }^{1}$ Institute of Arts and Humanities, Shanghai Jiao Tong University, Shanghai, China \\ ${ }^{2}$ Pan Tianshou Academy of Architecture and Art Design, Ningbo University, Ningbo, China
}

Correspondence Author: Ruixia Han, Institute of Arts and Humanities, Shanghai Jiao Tong University, Shanghai, China

E-mail: - annahan08@sjtu. edu.cn

Received date: 20 May 2019, Accepted date: 12 July 2019, Online date: 29 August 2019

Copyright: (c) 2019 Ruixia Han and Shaohua Huang., This is an open-access article distributed under the terms of the Creative Commons Attribution License, which permits unrestricted use, distribution, and reproduction in any medium, provided the original author and source are credited.

\begin{abstract}
When compared to the influence of internet collective action on politics in China, China's Internet literature is considered to be depoliticized. But is this really the case? This article analyzes the reasons for the "depoliticization" of Internet literature in China from the perspective of government regulation of the Internet, the operational mechanisms of internet literature, and the tastes of readers. In addition, based on the political attributes found in internet literature texts, the multiple ways in which politics is embedded in Internet literature, and the ways in which hyperlinks in Internet literature texts generate attention toward political issues, the article argues that Internet literature has not been completely depoliticized. Finally, the article shows that the lack of explicit political content of Internet literature is reflected in how it addresses the increased diversity and fragmentation of social consciousness, its pursuit of self-awareness, and its avoidance of political issues, reflecting a "realistic" attitude towards politics in China's current social milieu, and showing that "literature" and "politics" cannot be truly separated
\end{abstract}

Keywords: Internet literature, Chinese, Depoliticization, Internet regulation, Fragmentation

\section{INTRODUCTION}

With the rapid development of ICTs (information and communication technologies) in China, Internet-related topics have become a focus of discussion among scholars. One prominent area of discussion is focused on the Internet and politics. For example, Kluver and Chen conducted a topic analysis on academic journal articles related to the Internet in China and found that $39 \%$ were associated with political issues (Kluver, R., \& Yang, C, 2005). Several studies also show a close relationship between Internet use and political activities over the past decade. Yang argues that the Internet would bring a communication revolution that promotes civil engagement in politics through online activities (Yang, G., 2009:213). Zhou believes that the Internet serves as a platform for dissemination of bottom-up information and public debate (Zhou, X., 2009.). Xiao thinks that the Internet creates a quasi-public sphere in which state control is criticized, and collective action mobilized (Xiao, Q., 2011.). Esarey and Xiao claim that "the new media have empowered China's "netizens" and diminished the state's ability to set the public agenda and shape political preferences” (Esarey, A., \& Xiao, Q., 2011).

However, there are other studies showing that the Internet might not be so powerful in changing Chinese politics and that its impact is mainly on seeking approval for existing self-identity rather than pursuing an interest in politics. For instance, Damm argues that commercial interests instead of political motivations are the main driving force for Internet development in China, of which trivialization and de-politicization mark the main features of Internet content and usage (Damm, J., 2007). Norman Nie and Lutz Erbring asserted that network users spend so much time in front of their computer screens that they have fewer opportunities to personally interact with other human beings, and that is very likely to decrease their political engagement which usually requires social networks ( Norman, N., \& Erbring, L.,2000). As Habermas has mentioned, "In the context of liberal regimes, the rise of millions of fragmented chat rooms across the world tend instead to lead to the fragmentation of large but politically focused mass audiences into a huge number of isolated issue publics"(Habermas, J. ,2006)While China differs from Western liberal societies in its political system, the political support from the public opinion and public space is still critical for sustaining its regime legitimacy. This led Guo Liang to suggest that the Chinese Internet functions more like an "entertainment highway" (Liang, G.,2007). 
Citation: Ruixia Han, Shaohua Huang., The De-politicization of Internet Literature in China. Australian Journal of Basic and Applied Sciences, 13(8): 118-124. DOI: 10.22587/ajbas.2019.13.8.16

Conceptually, Internet literature refers to all forms of web-based writing, which issubjectively defined as literature by its authors and readers. It includes a wide range of genres, include works which are clearly "literary" and those who are not. A post in a personal blog may or may not be literature, and whether people view it as a literary work depends on subjective judgment. This makes Internet literature a matter of social construction, comprising a distinctive feature of non-seriousness (Yang, G. ,2010). Hockx defines Chinese Internet literature (CIL) as the Chinese language works "either in established literary genres or in innovative literary forms, written especially for publication in an interactive online context and meant to be read on---screen" ( Hockx, M.,2015:272). Compared with traditional literary works, Tse and Gong believe that Internet literature has two distinctive characteristics: authors are mostly nonprofessional and motivated by a desire for self-expression and genres include those that may not be popular in traditional literature (e.g., alternate history, contemporary fantasy, and xianxia) ( Tse, M. S., \& Gong, M. Z. , 2012). Many scholars believe the lack of seriousness in the Chinese context reflects the depoliticized character of Internet literature, but is this definitely the case? This article will focus on this issue to evaluate the current status of Chinese Internet literature and whether it can be really said to be "depoliticized."

\section{THE CURRENT STATE OF CHINESE INTERNET LITERATURE}

Internet literature emerged 20 years ago when the first literature website Under the Banyan Tree (Rongshuxia) was founded in 1997. Long-time readers have identified a number of stages in its development. The first stage is the nascent stage from 1997-2002, in which early members published representative works of Internet literature such as Jhi Hsin Tsai (Pizi Cai, The First Intimate Contact (Diyici Qinmi Jiechu), Hezin Jin's Wukong Zhuan, Murong Xuecun's Chengdu: Leave Me Alone Tonight and Changzhi Lin's Shaceng Diary. Half of those works appeared in BBS forums and made available to readers without charge. Most of the works are realistic in style, and they were heavily influenced by Chinese traditional literature which has non-fiction characteristics. Some rarely seen literature in this period, such as Fengzi Wuyu, was however, subject to the strong influence of Western, Japanese, and Korean literature. Popular works of Chinese Internet literature caught the attention of publishers and were later published as printed literature. The second stage was dominated by PC-based Internet literature between 2002 and 2010, where the landmark event was the foundation of Qidian.com. In this period, numerous works of literature emerged, creating a VIP commercial model for popular authors: online readers can read non-VIP author's work for free but need to pay for access to the works of VIP authors. Internet literature in this period gradually moved toward a paid subscription system, and many of the renowned websites were purchased by large online enterprises. At the same time, many cyber writers made their name and turned their writing activities into a successful career, such as Nomadic Toad, Tiancan Tudou, and Wang Yu. The third stage has been referred to "the mobile era of Internet literature," reflecting the redesign of many literature websites, including Tencent Literature, Baidu Literature and Cloudary Corporation for use on mobile devices. In fact, Internet literature has been rapidly commercialized with variety of business models that combine the markets of printed/online literature, online games, films, TV series, music theaters, comics, and other forms of intellectual property. For instance, the iconic writer, Tang Shan earned more than $\$ 17$ million dollars in 2015, the highest earning online author in China. The overall value of the Chinese Internet literature market has reached around $\$ 1.4$ billion dollars, and the number of readers has reached 450 million. Most of the readers are under 39 years old, and reading Internet literature has become an important online activity for Chinese netizens (Li, G. Q. ,2016).

\section{DE-POLITICIZATION OF CHINESE INTERNET LITERATURE AND ITS CAUSES}

Unlike other online activities, Chinese Internet literature features strong de-politicized characteristics. Politics, regardless from the perspectives of the author(s), readers, or the text itself, seems not to be the focus, particularly after the commercialization period started. Most have chosen themes designed to maximize entertainment value in order to increase their click through rate (CTR). According to the reports by Internet Literature Committee of the China Writers Association (CWA) at Chinawriter.com.cn, none of the top-10 selling works of Internet literature in the first half of 2016 have political themes. Some of these works are magic fantas y novels, such as Ever Night and Worthy of Respect in One Age, others such as I Shall Seal the Heavens and Priest belong to the wuxia and xianxia genres, while other such as Winter \& Summer and The Last Prince are romance fiction. Other works mix different genres. However, none of these works have obvious political themes.

We propose three main explanations to account for the depoliticization of Internet literature in China. The first explanation involves government regulation and control. Since the Internet started developing in China around 1990, the Chinese government has seriously focused on the issue how to regulate and control cyberspace information, physical data pipelines, and network revenue. Different from the control of physical infrastructure, controlling the Internet is an even more difficult task. It is widely believed that the central State Council and top Communist Party propaganda organs are in direct charge of Internet regulation and control, and therefore, aside from planning network construction and expansion, policy is primarily focused on standards development, production coordination, and promotion of the information economy (xinxi jingji). Therefore, it was not until 2000 that the Ministry of Information and Industry established guidelines regarding what should be deemed as sensitive. Those guidelines were not all-inclusive and many of the ministry's rules on Internet regulation and control were unpublished as of early 2000. During that period, the draft laws included provisions that anyone seeking to operate "Internet and multimedia network services" had to apply for a license from the authorities under the State Council. In October 2000, State Council decree 292 required ICPs to provide the authorities all content that appears on their sites as well as records of users who have visited their sites for up to 60 days prior to the request by demand. ICPs were responsible for policing their own sites for "subversive materials" ( Harwit, E., \& Clark, D. ,2001). Against this background, certain government information websites such as Xinhuanet.com pledged to "tighten control and delete 'harmful' material from Internet news reporting" in 2001 (Harwit, E., \& Clark, D., 2006). These measures generated widespread self-censorship among Internet users as well as service providers. Some ICPs even admitted that they actively checked the content appearing in the webpages 
Citation: Ruixia Han, Shaohua Huang., The De-politicization of Internet Literature in China. Australian Journal of Basic and Applied Sciences, 13(8): 118-124. DOI: 10.22587/ajbas.2019.13.8.16

under their server domains. For example, the founder of InfoHighway (a leading Chinese ISP company), Zhang Shuxin, stated in a 1996 interview that if the topics her audience addressed in discussion groups turned to be too political, then she will cut them off (Harwit, E., \& Clark, D. ,2001).

The Chinese government started implementing serious formal rules regarding Internet regulation and control since early 2000 , specifically associated with Internet services, content, and expression, aiming to establish a comprehensive system of regulatory norms for online behavior. For instance, Administration of Internet Publishing Tentative Provisionswhich came into effect in August 2002 clearly stipulated that "No unit or individual may commence in Internet publishing activities without permission." Also, Administrative Provisions on Internet Audio-Visual Program Service which went into effect in January 2008 required official permission for video and audio programming on the Internet. In addition, China has also set up an online filtering system, which takes place at access points, ISPs, and the backbone network, influencing Internet sites, email, forums, university BBS, social networks, blogging and microblogging services, real-time communications, and search engines. Filtered content includes pornography, political topics, and ethnic minority issues. These regulations prevent the possibility of political topics appearing in Internet literature.

In addition to these regulations, since 2011 the Public Security Bureau has also carried out several campaigns to "clean the Internet." For example, during the campaign in March 2013, Internet literature as well as online games and programming became targets, and many websites, such as gtxt.com, bixia wenxue, xiaoshuo tianxia, xiaoxiang shuyuan, and huaxia xiaoshuowang were found violating regulations for pornographic content. In another round of campaign in June 2014, numerous popular websites, such as 91 xiongmao kanshu wang, yanyu hongchen wang, the cuiweiju xiaoshuo wang and even the more highbrow Sina Books faced crackdowns for pornographic content. Although the stated goal of these actions was to "combat Internet obscenity," together with China's various Internet regulations, they also made online book distributors and authors more prudent in their choice of topics. As a result, it is very unlikely in practice that online novels with political themes will receive a wide distribution.

The second explanation for de-politicization of Chinese Internet literature is related to how the business models were operated and changing. As described above, the development of Internet literature can be divided into three stages: 1997-2002 period of individual publishing; 2002-2010 period of the personal computer, and the mobile reading period following 2010. During the first stage, the rise of Internet literature generally relied on the autonomous actions of writers and authors and was generally based on updating and following forums and email systems, without any commercial drives. In 2001, the first meaningful Internet literature website Ikong was established, marking the end of the "innocent age" of Internet literature. With the increased level of commercialism, the profit-making model gradually took shape. The leading site for online literature Qidian was established in May 2002 and introduced a VIP system in October 2003, allowing a large number of ordinary writers to make a living, while also making the Internet literature increasingly commercialized. In October 2004, Qidian was acquired by Shanda Interactive (盛大), investing a significant amount in the platform and heralding the arrival of a fully commercialized era of Internet literature.

The changes in the operating models of Internet literature has implications for restraints on the creative powers of writers of Internet literature. If the First Intimate Contact is representative of the first stage, Internet literature creators were mostly accidental, and motivated by "personal feelings." However, in the second and third stage Internet literature gradually became more "commercialized" and "specialized," the motivation of authors was increasingly motivated by market-driven click through rates. Because the rewards paid to authors by Internet literature platforms are largely determined by the popularity of the author, authors gradually become more commercially-minded writers, with work often jointly produced by "writers groups." Meanwhile, starting from around 2010, some popular online novels began to exercise "complete copyright" over content such as printing, film, and online games, as well as animation, electronic copyright distribution, and other peripheral products, increasing the focus to cater to the reader's interest and aiming for making more commercial profit. These trends further distance Internet literature from those structural issues that deserve greater public attention and discussion.

The third explanation is about the tastes "entertainment first" of Chinese readers in Internet literature. If the first stage of Internet literature in China could be called the "author stage," the second and third stages are certainly the "reader stages." If the meaning of literature can only be realized by the process of "reading", Internet literature during this period was operated by the capitalist logic of the "click through rate." As a result, Internet literature increasingly became about the "survival of the fittest", and the tastes of the readers decide what kind of work thrive and wither.

According to the statistics released from China Internet Network Information Center, until December 2015, the number of Chinese netizens had reached 687 million, with $75.1 \%$ of users between the ages of 10 and 39, and 89.3\% having a high-school or below level of education. An industrial report of Internet literature also pointed out that the majority audience of Internet literature was composed of under-39-year-old netizens, with this age group accounting for $80.2 \%$ of the overall audience, while university-educated and junior college-educated readers only accounted for $46.2 \%$ and $30.2 \%$ of the overall audience respectively (Li, G. Q. ,2016). The trend toward younger readers has profound impact on shifting preference for genres. Among all kinds of Internet literature, fantasy, martial arts, and romance ranked the top three, followed by magic-fantasy, wuxia-xianxia, romance, sci-fi, gaming, historical or military, urban workplace and fan fiction. The demographic characteristic of the audience and their reading preference exhibit a postliterature way ( Huang, H., 2002) of reading that features the style of "entertainment first", showing that the experience of Internet literature is a form of emotional communication or emotional catharsis, and that pleasure and distraction are the main reading objectives of consumers of Internet literature. This poses a sharp distinction from the intellectual motive of reading traditional serious literature that aims to acquire knowledge and education (Guo, Y., 2009). This means that it is difficult for political themes to gain acceptance in a marketplace focused on "entertainment first." The preferences of readers of Internet literature reflect this phenomenon. For example, according to a market report published in sootoo.com about Internet literature in China, the most popular genre is magic and fantasy $(63.1 \%)$, followed by wuxia and xianxia (52.9\%), romance (48.3\%), sci-fi (34.1\%), urban workplace (28.1\%), gaming 
Citation: Ruixia Han, Shaohua Huang., The De-politicization of Internet Literature in China. Australian Journal of Basic and Applied Sciences, 13(8): 118-124. DOI: 10.22587/ajbas.2019.13.8.16

(23.4\%), historical or military (18.6), fan (11.3\%), and others (7.6\%). No political novels were reported with a significant market share ( Li, G. Q. , 2016).

In a nutshell, government policy and regulation, together with the effect of market mechanisms and a culture of "entertainment first" among readers explain why political content is absent or not sought after in Internet literature. For example, Daria Berg has argued that online texts reflect the interplay of market forces, political pressures and artistic expression like traditional print ( Berg, D. , 2010).But has Internet literature become "depoliticized" simply as a result of the aforementioned change of reader's taste?

\section{INTERNET LITERATURE WAS NOT COMPLETELY DEPOLITICIZED}

As we have discussed earlier, while the depoliticization of Internet literature refers to the absence of political themes, this does not mean that politics is completely absent from contemporary Internet literature in China. Undeniably, none of typical political themes have become the main subject of Internet literature in China. From a global perspective, China has no such work as "The Gulag Archipelago" or "Silent Spring" that reflects on contemporary society or modernism. From a historical perspective, neither has China produced Internet literature similar to what was created in the twenties and thirties by leftist authors such as Lu Xun or Ding Ling, or the writers of the sixties and seventies praising socialism such as Guo Moruo. Following Derrida's concept of "an always already absent present," the lack of political themes or a clear political direction reflects a dominant mentality in Chinese society. The formation of this mentality is the result of the social structure and individual interactions. Under this context, politics should be viewed as an attribute rather than an actual object. Using the language of empirical social science, it should not be either 0 or 1 , but rather a continuous variable consisting of different values.

From this perspective, if we rate the political content of contemporary Chinese Internet literature on a scale from 0-100, we would not conclude that it is completely "depoliticized." In fact, within different themes, we can find different levels of involvement with political subjects. For example, in fantasy and martial arts Internet literature, the political content may be close to zero. However, in other cases, political content is unavoidable. Although these works do not touch directly on contemporary politics in China, they may include more general political themes. Writers in genres such as historical or military literature may employ various writing strategies that allude to historical events to attract readers' attention. For example, Stories about Ming Dynasty by Dangnian Mingyue describe China's last imperial dynasty with a Han Chinese emperor from its formation to its extinction, This work has all of the elements of popular internet literature but as researchers have pointed out, it cannot be described as fiction because it is a faithful retelling of the history of the Ming dynasty. In addition, while few in number, some works of internet literature have appeared that contradict mainstream views of history or political ideology, such as Reconstructing Empire and the National Sword.

In "Offense" and "Avoidance": An Analysis of the Spirit of Criticism in Internet Literature, Tan Dejing argues that there are two types of criticism in Internet literature - offense and avoidance. Offense means contradicting mainstream ideology, while avoidance means avoiding central discourses and focusing on entertaining readers. Tan believes that online criticism of Lu Xun and Yu Qiuyu was mainly about offense, while romance and martial arts novels are mainly about escape (Tan, D. J. , 2005). In fact, the relationship of political issues to Internet literature is more similar to the second type, meaning that it keeps a distance from central discourses in order to focus on pleasure and entertainment. However, this is not to say that Internet literature does not contain any "political" topics, Instead, through a process of transposing and collaging, many works of Internet literature feature popular interpretations of politics.

For example, in a well-known online forum in China, posters have given strategic recommendations on how to avoid political issues when creating Internet literature, such as not specifying the time period, or changing the names of the people or country involved. However, some posters have also ridiculed these suggestions, stating that unless a novel becomes very popular and is distributed widely, most people will pay no attention to it, and so authors can still be bold with what they write. These statements show a dilemma in novels with political themes. Under the influence of policy and market logic, novels with political themes are generally not popular. For both of the author and the reader, they all want to "avoid" political themes.

Nevertheless, even in Internet literature with non-political themes, we can still find some political allusions and clues in works that more directly address issues of government rules or corruption, such as No. 2 Chief, Organization Chief, and SASAC Chief, or involve with the development of Chinese society and international politics, such as National Policy. As to those most commonly found novels regarding urban workplace or female romance, the social context and relationship between characters also delineate changing power relations within society, indirectly reflecting certain political issues. For instance, in the popular network novel My Sunshine, which was also adapted into a TV series in 2014, the intractable situation of the female protagonist was a result of her high-ranking father losing his power. This reflects the actual situation of many children of senior officials living overseas nowadays. In addition, science fiction works which have won the prestigious Hugo Award in recent years The Three-Body Problem and Folding Beijing to varying degrees reflect China's political history and contemporary society. The Three-Body Problem starts with the Cultural Revolution, while Folding Beijing discusses the worsening social polarization in Beijing.

We derive a conclusion from the above discussion: as a product of social history, if works of Internet literature wish to obtain the sympathy and attention of readers, they must to a certain extent engage with China's history and contemporary political realities. "Politics" cannot be entirely removed from literature.

A major feature of the Internet is hyperlinks in the text. The production of Internet literature also creates a body of related texts. Taking the example of Folding Beijing, this work was serialized over only three days in the newsmth.netwebsite run by students at Tsinghua University and soon caught the attention of mainstream literary journals Zuifound and Fiction Monthly. Subsequently, the work was picked up by Ken Liu, the English translator of The Three-Body Problem, eventually winning the prestigious Hugo Award for science fiction literature. In other words, from its early beginnings as "grassroots literature" on a BBS forum, Folding Beijing quickly led to the generation of traditional texts as well as the creation of an English translation. Such kind of Internet literature 
Citation: Ruixia Han, Shaohua Huang., The De-politicization of Internet Literature in China. Australian Journal of Basic and Applied Sciences, 13(8): 118-124. DOI: 10.22587/ajbas.2019.13.8.16

created a series of linkages between different texts. In particular, after receiving the award, a large number of articles appeared on social media sites in China such as Weixin. Articles included titles such as "The Meaning of Folding Beijing: In the Future the Poor are Not Even Worth Exploiting." "Folding Beijing: A Social Commentary on Fixed Social Classes and an Unemployment Crisis", "Folding Beijing: A Metaphor for Class Separation and the Struggles of the Underclass in Modern Beijing", "Folding Beijing: A Torn Society", "Folding Beijing: An Atheist Social Commentary". Although these articles have different titles, they all point to the fear of class polarization and division in Folding Beijing. In other words, a novel that appeared as Internet literature produced extensive discussion that revealed social reality. This reveals the potentially "political" content of Internet literature.

If Folding Beijing is representative of a work of Internet literature that achieved fame and social impact, there are also many works that have achieved widespread popularity in online communities such as Baidu Tieba and Douban. For example, Daomu Biji, which has been recently adapted into a television drama, has attracted more than three hundred and sixty thousand netizens to focus and generates more than 100 million forum posts on Baidu Tieba. This vividly demonstrates that a popular work of Internet literature will also create new online communities and interaction, and these online communities are the foundation for developing political meaning in cyberspace.

Studies have pointed out that Internet information and technology are rebuilding Chinese society and identity (Yang, G., 2003). Many researchers believe that cyberspace activities are playing an active role in the evolution of Chinese society. As far as Internet literature is concerned, although many works are imaginary, they are still woven with themes such as the brotherhood code, gang killings, or ethnic conflict. In particular, novels about the lives of officials have an "intertextuality" with the CCP's current anticorruption fight. For example, Internet literature works such as Chinese Secretary, Beijing Office Director, and Reserve Cadre show themes such as power struggles, corruption, and the workings of officialdom. To some extent, these works reflect the contemporary focus on "power struggles" and "corruption". They are also providing an account of issues such as the distribution of power in society and officials' corruption from the perspective of Internet users. Those views act as a popular interpretation of the "logic of power" and a representation of contemporary "anti-corruption" campaigns, bridging the gap between those in power and ordinary citizens, as well as between official language and popular understandings. Highly influential works of Internet literature such as Folding Beijing also received attention from official media and government bodies after being popularized online.

\section{WHY CHINESE LITERATURE IS NOT COMPLETELY DEPOLITICIZED}

Many studies have regarded the rise of Internet literature as part of a youth subculture, arguing that the development of Internet literature is about satisfying the subcultural tastes of young people. In particular, as the field of Internet literature became increasingly commercialized, it was increasingly regarded as a "product." At the same time, a wide range of novels emerged catering to different tastes, from fantasy, to female romance, to gaming. In addition, different writing styles and subject matters all can be found within each category. For example, traditional female romance novels can be divided into two types of narrative mode: "innocent narrative" and "red narrative." Innocent narrative is a continuation of traditional literary romance, recreating beautiful and pure love with cyberspace. Red narrative strives for realism, writing about human vicissitudes. Combing different types of audience, Internet literature also features various forms of offline marketing. If Internet literature is regarded as a cultural "product," then we can find strong audience fragmentation and diversity in the entire process from "production" and "marketing" to "consumption."

From the audience's point of view, if their consumption of diverse Internet literature is seen as a way of life, or a unique way of life based on "values, desires, beliefs, needs, dreams and unique perspectives," the diversified nature of Internet literature consumptions reflects the diverse and fragmented characteristics of tastes on online consumption. In the 1980s, Bourdieu (1984) proposed the concept of "distinction" of "taste". A society made up of different tastes and preferences reflects the fragmentation and diversification of identification. According to Damm's analysis, the "fragmentation" of Chinese society is to some extent attributable to the multipoint-to-multipoint characteristics of the Internet (Damm, J., 2007).

The diverse choices in contemporary Internet literature to a large extent reflect the rise of "individual consciousness" among Internet users in China. As Ulrich Beck has pointed out, among both Europeans and Chinese themselves, there is a belief that Chinese society is dominated by collective identity. Since China's collective structure is a product of both Confucianism and communism, little space was given to individual actions and choices (Ulrich, Beck., 2010). However, the present reality is that Chinese society is becoming increasingly individualized_—not only is people's perception of the individual changing, people's expectations of individual freedom, individual choice, and individuality are also increasing. Beck also points out that China is becoming increasingly individualist as it moves towards a market economy, but this individualism does not extend to political participation (Ulrich, Beck., 2010). In fact, Internet literature have many advantages on "non-political" topics, reflecting the awakening of the individual consciousness of Internet users. As China's economy has gone through the stages of people's communes, the cultural revolution, and finally the reform and opening up and several political movements, the "depoliticized" themes of Internet literature has instead pursued individual values and desires.

During the 1950s, published works were dominated by dominated by works propaganda novels such as Struggles In An Ancient City, Keep the Red Flag Flying, and Railway Guerrilla that were written to legitimize communist party rule (Zhao, Q. P., 2010). In contrast, current works of Internet literature mostly deal with nonpolitical themes such as magic, emotions, and romance. Although political themes such as power struggles do appear, they are not related to contemporary politics in the PRC regime, but may relate to fictitious politics such as in the state approved drama In the Name of People about an anti-corruption campaign in a fictional Chinese city. The themes in these books are more individualistic and realistic, and are generally not linked to broader ideological questions, reflecting the aesthetic of "boredom with politics" found among many consumers of Internet literature. 
In his analysis of online freedom, Chinese scholar Hu Chunyang applies Bakhtin's carnival theory. From her point of view, Bakhtin's idea of the second life of the people is a very suitable way for understanding how people communicate in cyberspace ( Hu, C. Y. , 2006). In fact, this is precisely the source of the focus on entertainment in current internet literature, which is distinguished from the official, serious, and hierarchical real world. Internet literature has created a carnival world for ordinary citizens, in which the classes, property, family status, position, rank, age, and identity of the real world are forgotten, and in which the normal logic of everyday life can be reversed, blasphemed, ridiculed, teased, belittled, distorted and parodied, providing readers with a utopia of universal sharing, freedom, equality, and abundance.

As a result, the entertainment component of Internet literature seems to meet some need for spiritual freedom, at least on a temporary basis. Whether it would be fantasy or workplace romance, through the fate of characters in novels, people have experiences that they cannot enjoy in their real lives. In addition, themes that cover contemporary social relations and social conditions in China also allow the reader to both observe and reflect.

\section{CONCLUSION: LITERATURE AND POLITICS CANNOT TRULY SEPARATE}

A discussion of the depoliticization of Internet literature in China requires us to consider the relationship between "literature" and "politics." Although there is controversy about whether Internet literature is actually literature, as a product of society, it inevitably has a varying degree of relationship with "politics," and is located on the continuum between the pure aesthetics of literature and the political nature of literature. Reviewing the development of Chinese literature in the 20th Century, some writers consider this to be the "non-literature century." An important reason is due to the close association between literature and politics during this period, some researchers believe that literature lost its independence and purely aesthetic value, even lamenting the "death of literature." However, most researchers understand the development of Chinese literature in a broader context, arguing that the aesthetic characteristics of literature do not mean separation from politics. In fact, regardless of its relationship with politics, literature is a reflection of social structure, ways of thinking, and emotional state under a particular social context. Based on this a cognitive perspective, some scholars have divided the political content of 20th Century Chinese literature into eight stages: turn of the century (represented by Liang Qichao, Wang Guowei and Lu Xun etc.), the leftist decade between 1926-1936, the Yan'an period between 1935-1948, the first decade of the new China between 1950-1960, the literature change period between 1960-1978, the 1978-1988 period, the politicization of literature during the 1990s, and further politicization and development of literature after 2000 (Liu, F. J., 2014). In fact, regardless of whether literary theorists believe that literature should be depoliticized, literature cannot avoid reflecting the prevailing social and political reality. Regardless of whether "ideology" is used to describe the relationship between literature and the existing social system, literature reflects and interprets the existing social context. Using Internet literature to observe the current alienation from politics in China is also a reflection of the alienation of Internet users from contemporary political discourse in China.

However, an interpretation of Internet literature and China's current political context cannot be limited to a single type of text. In fact, through online communities, online space is becoming an important space for political participation. In contrast to the format of internet literature, hyperlinks based on actual events are widely dispersed and flexible, meaning they can better reflect the views of Chinese internet users toward important events. At the same time, Internet literature is one way of interpreting China's current political context. Interpreting China's current political situation from only one type of text is insufficient, therefore when considering the political meaning of internet literature in China, we must place Internet literature within the framework of other online events.

Acknowledgement

Humanities and Social Sciences Special Project of Shanghai Jiao Tong University (16JCWH09)

\section{REFERENCES}

Berg, D. , 2010. Consuming secrets: China's new print culture at the turn of the twenty-first century. In C. J. Brokaw \& C. A. Reed (Eds.), From woodblocks to the Internet: Chinese publishing and print culture in transition, circa 1800 to 2008, Leiden: Brill, , pp: 315332.

Damm, J., 2007. The Internet and the fragmentation of Chinese society. Critical Asian Studies, 39(2): 273-294. DOI: $10.1080 / 14672710701339485$

Esarey, A., \& Xiao, Q. , 2011. Digital communication and political change in China. International Journal of Communication, 5:298-319.

Guo, Y., 2009. On the expectations of Internet literature readers. Xinwen Chuanbo, 9:52-53.

Habermas, J. ,2006. Political communication in media society: Does democracy still enjoy an epistemic dimension? The impact of normative theory on empirical research. Communication Theory, 16(4):411--426. DOI: 10.1111/j.1468-2885.2006.00280.x

Harwit, E., and Clark, D. ,2001. Shaping the Internet in China. Evolution of political control over network infrastructure and content. Asian Survey, 41(3):377-408. DOI: 10.1525/as.2001.41.3.377

Harwit, E., and Clark, D. ,2006. Government policy and political control over China's Internet. In J. Damm \& S. Thomas (Eds.), Chinese cyberspaces: Technological changes and political effects, Abingdon, Oxon: Routledge, pp:11-37.

Hockx, M. ,2015. Internet literature in China. New York: Columbia University Press.

$\mathrm{Hu}, \mathrm{C}$. Y. , 2006. Freedom and imagination of freedom: A study of network in perspective of Bakhtin's carnival theory. Journal of Fudan University (Social Sciences), 1: 115-121.

Huang, H., 2002. From the age of classical literature to the age of post-literature. Wenyi Zhengming, 6: 37-39.

Kluver, R., and Yang, C, 2005. The Internet in China: A meta-review of research. The Information Society, 21(4):301-308. DOI: $10.1080 / 01972240591007616$ 
Li, G. Q. , 2016. 2015 Market Report for Internet Literature, Sootoo Research, February 22, 2016, Retrieved from http://www.liaoningwriter.org.cn/a/wangluowenxueredian/html/9264.html on $12 \mathrm{July,} 2017$.

Liang, G.,2007. Surveying Internet usage and its impact in seven Chinese cities. Center for Social Development, Chinese Academy of Social Sciences.

Liu, F. J. , 2014 . Why should we look at literature and politics again? Soochow Academic, 2014 (6): 95-101.

Norman, N., and Erbring, L.,2000. Internet and society: A preliminary report. Stanford Institute for the Quantitative Study of Society, 3:1419.

Tan, D. J. , 2005. 'Offense' and 'avoidance': An analysis of the spirit of criticism in Internet literature, Wenyi Zhengming, 4: 83-86.

Tse, M. S., and Gong, M. Z. 2012. Online communities and commercialization of Chinese Internet literature. Journal of Internet Commerce, 11(2):100-116. DOI: 10.1080/15332861.2012.689563

Ulrich, Beck. , 2010. "China is becoming politicized and should develop Chinese cosmopolitanism", Oriental Outlook Weekly, August 4, 2010. Retrieved from http://finance.ifeng.com/opinion/hqgc/20100804/2478791 on $12 \mathrm{July,} 2017$.

Xiao, Q., 2011. The battle for the Chinese Internet. Journal of Democracy, 22(2): 47-61. DOI: 10.1353/jod.2011.0020

Yang, G. , 2003. The co-evolution of the Internet and civil society in China. Asian Survey, 43(3):405-422. DOI: 10.1525/as.2003.43.3.405

Yang, G. , 2010. Chinese Internet literature and the changing field of print culture. In C. J. Brokaw \& C. A. Reed (Eds.), From woodblocks to the Internet: Chinese publishing and print culture in transition, circa 1800 to 2008, Leiden: Brill, pp: 333-352.

Yang, G., 2009. The power of the Internet in China: Citizen activism online. New York: Columbia University Press.

Zhao, Q. P., 2010. The politicization of desire and the desirability of politics: On the narrative interaction between the language of war and the semantics of love in seventeen years," Modern Chinese Literature Forum Vol. 1. January 22, 2010. Retrieved from http://www.chinawriter.com.cn/2010/2010-01-22/81749.html on 12 July, 2017.

Zhou, X. , 2009. The political blogosphere in China: A content analysis of the blogs regarding the dismissal of Shanghai leader Chen Liangyu. New Media \& Society, 11(6):1003-1022. DOI: 10.1177/1461444809336552 